\title{
Exploring the development of environmentally sustainable products through reward-based crowdfunding
}

\author{
Filippo Corsini ${ }^{1}$ (D) Marco Frey ${ }^{1}$
}

Accepted: 24 August 2021

(c) The Author(s) 2021

\begin{abstract}
Literature on crowdfunding is rapidly expanding by exploring typologies of crowdfunding projects, success factors of the projects, and how success factors might change depending on the project typologies. Firstly, based on the literature that suggests crowdfunding platforms provide a good alternative for financing innovative ideas, the present exploratory research aims to analyze how the crowdfunding instrument has been used in supporting the development of sustainable products. Secondly, based on researches that focus on success factors of crowdfunding campaigns, the present work aims to explore the success determinants of projects developing sustainable products. The results of the investigation show that the impact of crowdfunding in supporting the development and commercialization of sustainable products is quite marginal and only a few successful projects showed a high impact potential to contribute to the pathway to more sustainability by directing influencing incumbents. Moreover, through an in-depth examination of the campaigns aimed at developing sustainable products, we found that adopting just a generic keyword (i.e. sustainable, ecologic) to describe a sustainable product might weaken the success probability of the campaign. In light of the results achieved, the paper formulates some managerial suggestions illustrating how crowdfunding platforms could stimulate the collection of more environmentally friendly projects.
\end{abstract}

Keywords Crowdfunding · Environmental sustainability · Green financing · Sustainable product $\cdot$ Product design

Filippo Corsini

filippo.corsini@santannapisa.it

Marco Frey

marco.frey@santannapisa.it

1 Scuola Superiore Sant'Anna (Sant'Anna School of Advanced Studies), Istituto di Management (Institute of Management), 56127 Pisa, Italy 


\section{Introduction}

In the last three decades, the increase in environmental pollution [1], global warming [2], depletion of natural resources [3], inadequate waste disposal [4], deforestation and loss of biodiversity [5] have become recurrent issues on the global agenda, and the concept of environmental sustainability has started to emerge consistently [6]. In general terms, the concept of environmental sustainability originates from the definition of sustainable development provided by the World Commission on Environment and Development: "meeting the needs of the current generation without compromising the ability of future generations to meet their needs" [7]. In other words, environmental sustainability could be defined as "a condition of balance, resilience, and interconnectedness that allows human society to satisfy its needs while neither exceeding the capacity of its supporting ecosystems to continue to regenerate the services necessary to meet those needs, nor by our actions diminishing biological diversity" [8].

In order to reach environmental sustainability on a global level, the role of businesses is relevant. Global environmental and industrial policies, during the last decades, have evolved accordingly as a means of optimizing the consumption of natural resources and improving firms' environmental performance [9]. Companies themselves are also recognizing the need to act on environmental sustainability due to the increasing scarcity of many resources that for centuries were believed abundant and thus exploited indiscriminately. Within this context, several approaches have been adopted by firms such as industrial symbiosis (i.e. exchanges of waste or by-products between different companies) [10], sustainable open and closed-loop supply chains (i.e. supply chains aiming at closing material flows thereby limiting resource extraction and waste production) [11], waste minimization (i.e. waste management approaches focusing on reducing the amount and toxicity of waste generated) [12] or the use of recycled materials [13]. Since design represents a crucial phase in the lifecycle of a product in which environmental performance can be strongly influenced, several businesses have also started to introduce initiatives related to the design of sustainable products. The goal of such approaches is to minimize the environmental impact of a product during its entire lifecycle-from the acquisition of materials to the production, the use to end of life management-without compromising other essential criteria of the product such as functionality, performance, quality or other technical aspects. Indeed, during such a phase, critical decisions are made on the main characteristics of the product such as materials used, energy required, recyclability and longevity [14].

As suggested by Ortas and colleagues [15], the lack of funding might represent a fundamental barrier to develop environmentally friendly projects, especially related to the development of new products. Such a barrier is perceived in different industrial sectors and different geographical contexts. For instance, Salo and colleagues [16] underlined the relevance of the lack of funding in developing environmentally friendly products in textile and information technology industries in the Nordic countries while Singh \& Sarkar [17] reported the same problem (i.e. lack of 
funding) in developing new environmentally friendly products in an Indian ring and piston manufacturing company.

In such context, crowdfunding (i.e. a mechanism where organizations attempt to undertake a specific project relying on funding collected from other individuals) may provide a large contribution to the development of environmental-oriented products. Indeed, several authors [18, 19] support the view that crowdfunding financers are moved by different types of motivation quite dissimilar from those of professional investors, such as the wish to support environmental or social causes [20]. These days, crowdfunding initiatives range from the support of cultural enterprises to aid in response to humanitarian crises, from scientific research to more general, and supporting any typology of innovation aimed at breaking down the traditional barriers of financial investment.

Literature on crowdfunding is expanding rapidly at present time; however, studies examining how the instrument of crowdfunding has been used for developing sustainable products is currently under-represented in the literature [21, 22]. The present exploratory research offers an opportunity to bridge this gap by analyzing projects concerning the development of sustainable products seeking financial support in the two largest crowdfunding platforms to date (i.e. Kickstarter and Indiegogo). In more detail, this exploratory research aims at making a first step in the analysis of sustainable crowdfunding projects by exploring how reward-based crowdfunding platforms are used to develop sustainable products by reducing barriers that businesses usually encounter in adopting such sustainability pathways (with a clustering analysis), and also exploring the success determinants of these projects (with a logistic regression).

The paper is organized as follows: the next section provides a brief overview of the field under analysis. In more detail, in Sect. 2.1 we reviewed the existing literature to classify different typologies of sustainable products; in Sect. 2.2 we reviewed the relevant literature supporting how reward-based crowdfunding might sustain the development of environmentally sustainable products and we formulated the research question; then in Sect. 2.3 we reviewed the literature on success factors in reward-based crowdfunding campaigns and we formulated hypotheses to be tested in the field under analysis. The methodological section then provides information about the data and the methodologies used to conduct the research. Results and discussions are presented in section three. Finally, the concluding section provides suggestions on the role of crowdfunding in stimulating the collection of more environmentally friendly projects.

\section{Literature review}

\subsection{Environmentally sustainable product development}

The transition towards environmental sustainability encompasses modes of production and the consumption of products. In such context, sustainable products [23] have gained increasing recognition over the last few years. Sustainable products are ideated considering the whole lifecycle of a product and addressing environmental 
concerns related to production, consumption and dismantling [14]. The specific objectives of product sustainability can vary according to the products; however, literature available in this field does identify different aspects that can be addressed.

Mestre \& Cooper [24] suggest that a product, in order be environmentally sustainable, should be made from low-impact materials. This means that a product should be designed to foster efficiency in the use of resources, for example, through the replacement of raw materials with renewable or recycled ones [25], or through the reduction or elimination of materials that can be dangerous to the environment (e.g. lead, mercury, chromium and cadmium) [26].

Another option when making environmentally sustainable products is to design them to have the longest possible lifespan. This means designing products to be retained in the economic system as long as possible, whilst conserving or improving their value during their entire life [27]. According to the available literature on the topic, products with a long life are designed to be durable i.e. the product must take wear and tear without breaking easily [27]. Modular, upgradeable and easily disassembled products are also designed to have a long lifespan [28]. Moreover, long-life products are designed to be repairable (i.e. putting actions in place to ensure a damaged product can be repaired and used again) [29] or regenerable/re-manufacturable which is an industrial process that allows used products to become useful again through actions encompassing replacement of parts or updating [30]. A product can also be grouped in such a category if it is easily reusable, which means that the whole product or parts of it can be used for other activities [31].

An additional way to make a product environmentally sustainable is to develop it in a way that allows the materials to be continuously recycled into new ones [27]. Allowing a product to be easily recyclable is also described in the literature as "closing the loop" [32]. According to the literature [33] a product or a component might be subjected to an upcycling process, which is an approach that converts them into higher-quality materials and/or with increased functionality. Alternatively, downcycling is an approach that converts a product or a component into lower quality materials. Even if upcycling is the preferable option, such a choice is not always possible. Similar to the concept of recyclable products, some products are biodegradable or compostable [32]. Such products are made of biological or organic materials that, at the end of their use, can be safely returned to the biosphere without generating waste [34]. According to Vert and colleagues, [35] biodegradability is the capacity of a certain product to be degraded by biological activity, while compositing is the process, enacted by microorganisms such as bacteria or fungi, where organic products or components are biologically decomposed.

The last option for making an environmentally sustainable product is in regards to containing the consumption of resources during the usage of the product. Such an approach means designing a product to increase the efficiency in the usage phase, for example by reducing the final user's consumption of energy [36] but also realizing a product that is fuelled by renewable energy sources such as solar or wind power [37]. A product that is made for containing the consumption of resources is also a product for which the material management is 
optimized for consumables or additional components that are employed during its entire lifecycle [38].

In conclusion, the reviewed literature allows us to classify sustainable products in the following categories: products made from low-impact materials, long-life products, recyclable products, compostable or biodegradable products, and use efficient products.

\subsection{Reward-based crowdfunding for supporting the development of environmentally sustainable products}

The term "crowdfunding" has been developed from the term "crowdsourcing", which describes a web-based innovative model that involves voluntary open collaboration in the development of creative products or solutions [39]. Crowdfunding has been defined by many authors [40-42] as a mechanism where individuals, firms or general organizations attempt to undertake a specific project relying on funding collected, usually with the help of an internet platform, from other individuals.

Belleflamme and colleagues [18] have identified different forms of crowdfunding typologies distinguishing between "non-investment-based models" and "investmentbased models". According to the authors, "non-investment-based models" groups' crowdfunding campaigns can be either donation-based or reward-based. The donation-based model is characterized by individuals wishing to support a determinate project making donations to the campaign without expecting anything in return. Marchegiani [43] claims that such support is based on a sort of "micro-mecenatism" attitude of individuals. Donation-based crowdfunding campaigns are quite often adopted for financing either philanthropic or particular research projects [44].

The reward-based model, on the other hand, is based on an agreement in which the supporter of a campaign has, in return for a financial contribution, a non-financial benefit generally fixed in advance by a proponent of the campaign. Generally, most reward-based crowdfunding campaigns offer the possibility to pre-order a product in advance before it is available to the general public [18]. Nowadays, most known platforms for hosting crowdfunding campaigns, such as Kickstarter and Indiegogo, adopt mainly a reward-based model [43]. In more detail, in Kickstarter and Indiegogo platforms' project creators choose a deadline and a minimum funding goal for their project. To thank their financers for their support, project creators offer a reward, that generally consists of gaining access to a product before it is available to the general public. Both platforms operate under an "all-or-nothing rule" by which project creators only receive money if the total amount raised by the end of the campaign is either equal to or exceeds the minimum funding goal identified at the beginning of the campaign.

According to Belleflamme and colleagues [18], there are also other typologies of crowdfunding activities that can be grouped as "investment-based models". These can be differentiated as lending based, royalty-based, or equity-based. In such models, individuals are offered a share of the future profit in exchange for an in-advance economic contribution. 
Literature on the topic suggests that crowdfunding platforms, especially those based on a reward-based model, provide a good alternative for financing innovative ideas and products that might have been difficult to develop with traditional financing channels [45-47]. In contrast with traditional financing instruments, crowdfunding financers can be pushed, for instance, by the willingness to support an environmental cause instead of the mere financial outcome, then bear higher risks for supporting an innovative project [20].

Reward-based crowdfunding platforms can represent a good alternative for developing sustainable products by reducing barriers that, in general, businesses encounter when adopting a sustainability pathway. Research conducted by Van Hemel \& Cramer [48] assessed the barriers to sustainable product development strategies in firms. The authors identified that the main barrier is the presumption that some types of sustainable products have not yet been requested by customers. This leads to the suggestion that firms perceive environmental customer demands as one of the most important drivers for starting a sustainability pathway. Given the necessity that firms understand the interest of consumers in advance, the contribution of crowdfunding platforms might be relevant. Indeed, a crowdfunding campaign can serve as a marketing research tool. A crowdfunding campaign relies on individuals committing their own money to risky projects, thus informing the project creators about the market potential of the newly proposed product ideas. It also serves to pre-test the market uptake of a potential new product $[49,50]$. On the other hand, a rewardbased campaign might serve as a signaling instrument to highlight market uncertainty for a certain product [51].

More recently, Rousseaux and colleagues [52] also explored the barriers to sustainable product development strategies in firms. In this instance, the authors identified a lack of economic resources as a relevant barrier for the implementation of sustainable product development strategies, especially in SMEs. They also noted that the contribution of crowdfunding platforms might be relevant as instruments that allow advance-selling of a product. Many reward-based crowdfunding platforms allow a pre-ordering mechanism on products that can stimulate sales in the first stages of product development (even a prototype), thus financially supporting the further development of the product [19].

Finally, Rossi and colleagues [53] explored the barriers to sustainable product development strategies. The authors suggest that several companies manifest problems in identifying the environmental aspects to address in product development, and have difficulties in matching functional product requirements and sustainability goals. Crowdfunding platforms, as tools for helping to collect feedback on products, might be relevant as instruments to reduce such barriers. Indeed, having prompt feedback from their customers could help them to address these issues by adopting a sort of co-design process. Co-design has been defined as the "collective creativity as it is applied across the whole span of a design process." [54] In other words, a process in which product designers use the ideas generated by others as sources of inspiration and innovation. Many crowdfunding platforms allow direct interaction between project creators and financers, and such interaction might represent a good instrument for stimulating co-design and receiving useful feedback on how 
to improve the product by suggesting how to incorporate relevant environmental enhancements [55].

Considering the aspects presented above, crowdfunding might represent a remarkable channel for financing and developing sustainable products for different categories of environmentally oriented firms like the ones proposed in the framework by Schaltegger [56, 57] and Petersen [58]. In such a framework, entrepreneurial activities are distinguished between activists, bioneers and ecopreneurs. Activists are non-professionals who crowdfund in their leisure time. Bioneers aim at being profitable ventures but are operating in market niches and thus serving the specific customer needs of these niches. Finally, ecopreneurs run conventional companies and aim at high and growing market shares. Crowdfunding initiatives, allowing projects ranging from individual designers and inventors to large corporations that want to test new product ideas, can be managed successfully by activists, bioneers and ecopreneurs.

Unfortunately, at the present time research on this topic is still underrepresented in the available literature. Yet in the last few years, several conceptual studies have started to appear on the topic. For instance, Petruzzelli and colleagues [21] conceptualized the implications of crowdfunding for sustainability by providing a guide to better understand the relevance of the crowdfunding phenomenon for sustainable initiatives. Testa and colleagues [22], also with a conceptual study, discussed how crowdfunding might represent a novel socio-technical practice with the potential of upscaling and transforming financial and sustainability regimes. However, empirical research is still missing. An interesting investigation has been conducted by Vismara [59] analyzing equity crowdfunding. The author provides evidence of the attractiveness of sustainability-oriented ventures in equity crowdfunding; moreover, he suggests that although sustainability orientation does not increase the chances of success in engaging professional investors, it attracts a higher number of restricted investors.

So far, to the best of our knowledge, there is no empirical research investigating the contribution of reward-based crowdfunding to sustainable product development. Given the framework presented above, the research question addressed in the paper is:

RQ1 How has the crowdfunding instrument been used in the development of environmentally sustainable products?

\subsection{Success factors in reward-based crowdfunding campaigns}

Previous research has investigated how certain project characteristics might influence the success of a crowdfunding initiative. There are studies explicitly focusing on whether the depth of information disclosed about the project might determine the funding success $[60,61]$. Other studies focused more on general project characteristics such as the amount requested and the length of the campaign [62-64]. Finally, other researchers focused on both aspects [65]. Success factors of crowdfunding campaigns were also investigated in relation to different typologies of projects. For 
instance, Cordova and colleagues [66] investigated the success of technology-related projects, Beier \& Wagner [67] in tourism-related projects, de Larrea and colleagues [68] on the success of restaurant crowdfunding. As the determinants of success in crowdfunding campaigns for the development of sustainable products have not been explored by the literature yet to the best of our knowledge, the present research also aims at bridging this gap.

Several researchers investigated how the amount requested in the crowdfunding campaign could predict the success of the initiative [63, 66, 69]. Those researchers agree that there is a negative correlation between the funding goal and the probability of success. Indeed, it has been noticed that the amount requested is a proxy variable of the complexity of the project and more complex projects require greater confidence of financers in supporting the project, and thus to the probability of collecting less funds [65]. To assess if the amount requested negatively influences the success of crowdfunding campaigns in supporting the development of a sustainable product, we formulated the following hypothesis:

H1 The amount requested in a crowdfunding campaign for supporting a sustainable product is negatively related to the success of the initiative.

Another factor generally investigated in assessing the success of a crowdfunding initiative is the duration of the campaign. Most of the research on the topic suggests a negative influence of the variable on the success of the project; the longer the funding period, the less likely the probability of success $[61,63,65]$. However, in this case the literature available on the topic is not completely in accordance. For instance, Cordova and colleagues [66], in analyzing more than a thousand technology projects hosted in several different crowdfunding platforms, highlighted that project duration increases the chances of success. In the field under investigation, in order to assess how the duration influences the success of crowdfunding campaigns, we therefore formulated the following hypothesis:

H2 The duration of the crowdfunding campaign supporting a sustainable product is negatively related to the success of the initiative.

Some of the previous studies exploring the success of crowdfunding initiatives are grounded on the information diagnosticity theory. This theory suggests that the more a webpage provides sign in helping consumers to reduce the barriers and bias emerging from the absence of physical assessment of a product, the more the information provided is perceived as diagnostic for the ability to facilitate a decent evaluation of the real quality of the product [70, 71].

In more detail, the information diagnosticity theory explores whether the amount of information published has a positive influence on the sale of a product or not [72]. In crowdfunding campaigns, project creators are used to publishing a description about the product itself and the overall process leading to the realization of the product. In such a way, potential financers are facilitated to assess the project and support their funding decision. Previous research investigating the 
general success factors of crowdfunding projects generally agrees that the longer and more complete the description of the project is, the higher is success probability $[73,74]$. In the context under investigation, to the best of our knowledge, such a relationship between information diagnosticity and success has not been investigated. Therefore, the following hypothesis can be formulated:

H3 The number of words used to describe the project campaign for supporting a sustainable product is positively related to the success of the initiative.

Research grounding on the information diagnosticity theory also suggests that it is not only the amount of textual information published that has a positive influence on the sale of a product. For example, Özdemir and colleagues [75] suggest that utilizing images and videos by indicating the crowdfunding plans can help to better depict funding initiatives and might be very appropriate in ensuring the success of the project.

When it comes to an environmentally sustainable product, a technical description made with some specific keywords of the materials used (e.g. recycled) or the technical characteristics of the product itself (e.g. durable, energy-efficient) could better represent the relevant information for a crowdfunding campaign. In detail, adding specific terms (e.g. recycled, durable, energy-efficient) might facilitate the evaluation of the environmental qualities of the product and stimulate confidence that supporting the product will also be good for the planet, thus encouraging potential supporters' funding decision grounding on their environmental awareness.

On the one hand, the environmentally friendly soundness of a project can be expressed by some generic keywords (i.e. sustainable, ecologic) that do not provide much information as to the environmental characteristics of the product. This typology of generic labeling also happens widely with the promotion of regular products [76]. On the other hand, the environmentally sustainable characteristics of a product can be described in detail mentioning specific keywords (e.g. repairable, made of recycled material). Such precise information could better support the evaluation of the attributes and the actual quality of the product, and be helpful in the decision-making.

General research on crowdfunding, grounding on the information diagnosticity theory, only tested whether the amount of text and the presence of images or videos have a positive influence on the sale of a product. For this reason, aiming also at contributing to the information diagnosticity theory, we propose the following hypothesis to be tested:

H4 There is a positive relationship between the adoption of specific keywords describing in detail the sustainable attributes of a product and the success of the crowdfunding initiative. 


\section{Data collection and methods}

\subsection{Data collection}

Data related to the projects seeking financing support on Kickstarter and Indiegogo was retrieved using the data provided by Webrobots.io [77] which is a web scraping company that has datasets of Kickstarter and Indiegogo projects starting in 2009. Data available consists of features such as Name of the project, short description of the project, date of launch of the project, deadline of the project financing campaign, main category of the project, country of origin of proponents, currency, number of campaign financers, amount raised by the campaign, amount requested in US dollars in the crowdfunding campaign, final status at the end of the campaign (funded or not) and the project link (useful to retrieve other relevant information like the description of the project). The datasets contain in total more than 200.000 projects for the period from 2009 to 2020 .

In order to identify projects aimed at the development of products only and excluding, for instance, campaigns for supporting the environment, a first selection of projects has been undertaken using the categories that both Kickstarter and Indigogo utilized to divide the projects.

Then, a set of keywords, grounded on the literature review on sustainable products presented in Sect. 2.1, were used to identify only projects pertinent to the investigation. In detail, the search procedure was conducted by seeking those keywords in the fields related to the name of the project and the description of the project. More in detail, the keywords used were those presented in Table 1.

Moreover, in order to intercept the more generic projects, the keywords "ecolog*" and "sustainabl*" were used.

The filtering process adopted allowed us to identify 3082 projects strictly related to sustainability published on both platforms from 2009 to 2020. Such a small amount (which represents about $1.5 \%$ of the total projects published on both platforms) underlines the paucity of projects supporting the development of sustainable products in such a time frame.

Table 1 Keywords used to retrieve projects on Kickstarter and Indiegogo databases

\begin{tabular}{lll}
\hline $\begin{array}{l}\text { Sustainable product specifications } \\
\begin{array}{l}\text { Products made from low impact materi- } \\
\text { als }\end{array}\end{array}$ & Support references & Keywords adopted for searching projects \\
Long-life products & {$[28-31]$} & biol*, recycled, renewable material* $^{*}$ \\
& $\begin{array}{c}\text { durab*, repair*, remanufactur*, } \\
\text { upgradab*, modular*, reusab*, disas- } \\
\text { sembl* }\end{array}$ \\
$\begin{array}{l}\text { Recyclable products } \\
\text { Compostable or Biodegradable products } \\
\text { Use efficient products }\end{array}$ & $\begin{array}{l}{[32,33]} \\
{[32,34,35]}\end{array}$ & $\begin{array}{l}\text { compostab*, biodegradab* } \\
\text { energy efficien*, renewable energy }\end{array}$ \\
\hline
\end{tabular}




\subsection{Clustering procedure}

In order to gain a more in-depth understanding of how the crowdfunding instrument has been used in the development of sustainable products, the projects identified were classified using a cluster analysis. In detail, the variables have been used to divide the project into clusters, as follows:

(1) Number of campaign financers. This information is described by a continuous variable representing the number of financers that decide to financially support a certain project by bearing a risk and expecting a final reward.

(2) Amount raised by the campaign (i.e. contribution raised by the campaign). Such information is represented by a continuous variable illustrating the amount (in US dollars) of the contribution payments made by the financers to support the campaign via a regular bank payment or a micropayment provider.

(3) Amount requested in the crowdfunding campaign (i.e. the goal). Such information is represented by a continuous variable depicting the target of the crowdfunding campaigns. Indeed, such campaigns should advertise a target for the amount of money they want to raise.

(4) Project status. A binary variable has been constructed to represent the final state of the project: successful or unsuccessful. For successful projects, the variable was set equal to 1 , while for unsuccessful projects it was set equal to 0 . It has to be specified that in the investigation it has been decided to only consider projects that ended the collection campaign and to exclude those projects still live, canceled or suspended.

(5) Sustainability keyword specificity. A binary variable was constructed upon the above-mentioned keywords identified to collect the projects, which allowed us to differentiate between projects adopting fairly generic sustainability keywords (i.e. sustainabl*, ecolog*) and those adopting rather more specific sustainabilityrelated keywords (e.g. biol*, recycled, renewable material*, repair*). In more detail, for projects just adopting the generic keywords sustainabl* and/or ecolog* the variable was set equal to 0 , while for the projects adopting a more specific sustainability-related keyword for describing the project (e.g. biol*, recycled, renewable material*, repair*) the variable was set equal to 1 .

By identifying homogeneous groups of projects, this approach is useful in describing how the crowdfunding instrument has been used in the development of sustainable products. Each cluster is mutually exclusive and has the maximum differentiation between project groups and the maximum homogeneity within each project belonging to the same group [78]. According to Makles [79], when the number of clusters is unknown, the best option to assess the optimal number of clusters is computing and comparing different solutions, using two approaches to detect the optimal cluster:

(1) A scree plot and search for a kink in the curve generated from the within the sum of squares (WSS) or its logarithm [log (WSS)] for all cluster solutions. 

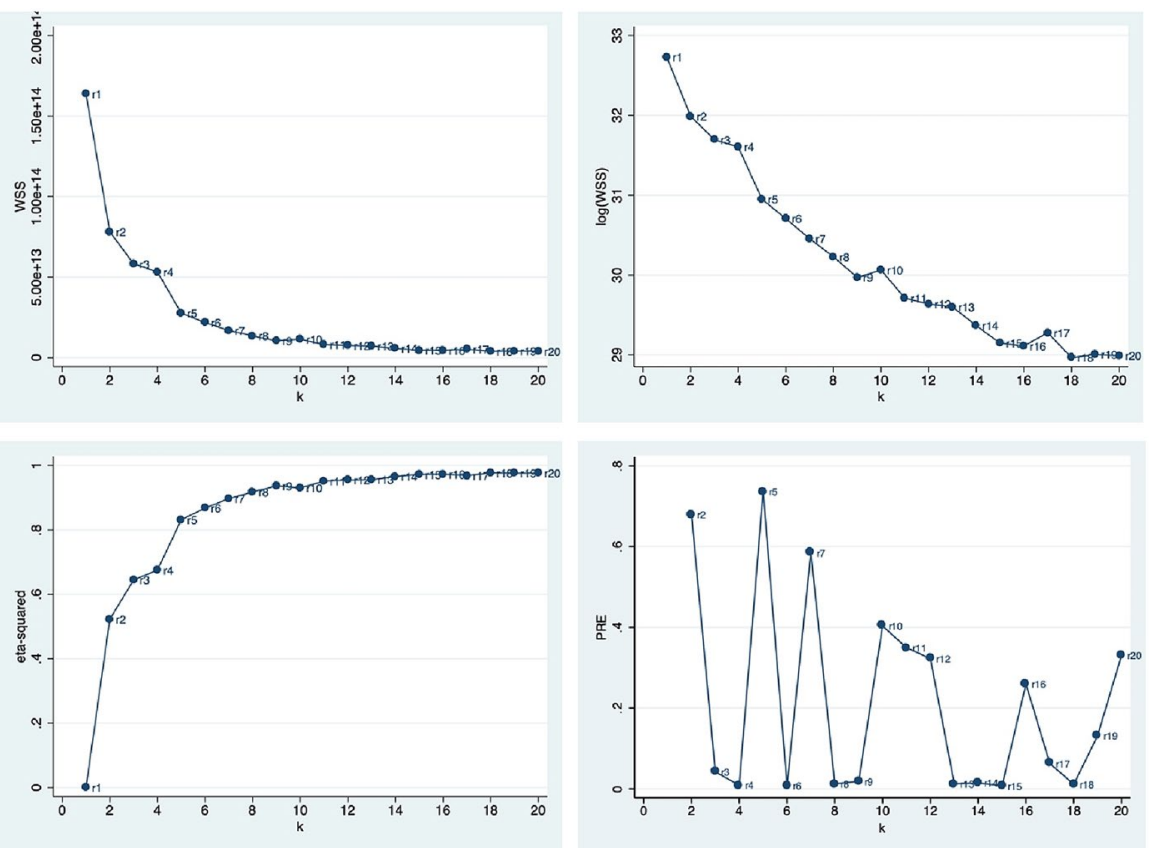

Fig. 1 Assessment of the best clustering option

(2) Assessing the $\mathrm{h} 2$ coefficient or the proportional reduction of error (PRE) coefficient [80].

Figure 1 highlights that five clusters represent the optimal solution. Then, a $\mathrm{K}$-means clustering approach was used to allocate the 3082 projects into five clusters. K-means is a clustering approach that divides observations into clusters so that each observation belongs to the cluster with the nearest mean. K-means clustering also specifies the number of clusters and is especially useful when grouping cases with similar characteristics [78].

\subsection{Multivariate regression analysis}

To test the hypotheses and also to better understand the success determinants of sustainable projects, a logistic regression analysis has been conducted. Regression analysis allows for investigation of the relationships between a dependent variable and several independent variables, indicating if the independent variables have a significant relationship with the dependent variables and the relative strength. Logistic regression is then used to model dichotomous outcome variables. 
In regression analysis, two variables may be in a perfect linear combination with one another. This problem is called multicollinearity, and if it increases the regression model estimates, the coefficient becomes unstable and the standard errors for the coefficient may be inflated. Thus, the presence of collinearity by computing the tolerance and variance inflationary factors (VIFs) for all variables was checked as suggested by O'Brien [81]. Low variance inflation factors $(<2.0)$ and a VIF less than 5 revealed that multicollinearity was not present in the empirical model.

\section{Results and discussion}

\subsection{Cluster taxonomy}

This section presents the results of the cluster analysis. It shows how the projects were distributed into the clusters and provides a description of clusters using the literature available. The composition of the five clusters in terms of projects is presented in Table 2, while Table 3 shows some descriptive statistics of the five clusters.

Cluster 1 is characterized by a small percentage of projects not financed with smaller than average support received both in terms of amount raised in the campaign and the number of financers. Projects grouped in this cluster are also marked by a sensibly over-average amount requested in the crowdfunding campaign. It is interesting to note that all of these projects adopted quite generic sustainable keywords to describe their product. Literature on crowdfunding [82] suggests that first-time crowdfunders might often be biased with an availability effect, and as a consequence are likely to identify excessively optimistic amount requests for their projects. The availability effect refers to the tendency to judge events to be more likely or frequent when instances thereof come more easily to mind [83]. In recent years, crowdfunding has been receiving consistent attention from the media, and examples of successful campaigns are often overrepresented. First-time crowdfunders can thus be biased in estimating the likelihood of success and the number of resources that can feasibly be raised through crowdfunding and be over-optimistic for their product. Checking the number of campaigns started by the project proposer in this cluster confirms this interpretation. Such behavior easily fits with the adoption of a quite generic sustainable keyword. Indeed, also in recent years, the demand for environmentally friendly products has steadily grown in customer and consumer

Table 2 Composition of the five clusters

\begin{tabular}{lccl}
\hline Cluster $^{\circ}$ & $\begin{array}{l}\text { Number of } \\
\text { projects }\end{array}$ & Percentage (\%) & $\begin{array}{l}\text { Cumulate } \\
\text { percentage } \\
(\%)\end{array}$ \\
\hline 1 & 27 & 0.88 & 0.88 \\
2 & 1110 & 36.03 & 36.90 \\
3 & 88 & 2.86 & 39.76 \\
4 & 421 & 13.66 & 53.42 \\
5 & 1435 & 46.58 & 100 \\
\hline
\end{tabular}




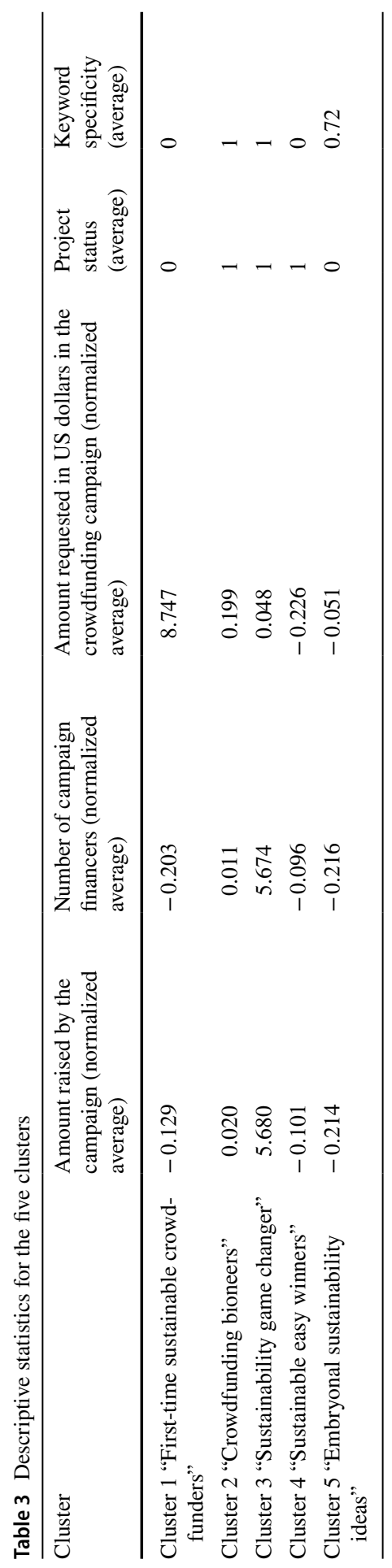


expectations [84, 85], and the bias of first-time crowdfunders can be increased when they aim at commercializing high-demand products such as sustainable ones. For all the reasons presented above the cluster can be named as "First-time sustainable crowdfunders".

Cluster 2 groups a relevant percentage of projects successfully financed with slightly higher than the average support received, both in terms of amount raised in the campaign and number of financers. Projects grouped in this cluster are also marked by a slightly above-average amount requested in the crowdfunding campaign. It is interesting to note that all of those projects adopted quite specific keywords to describe their sustainable product. As presented in Table 4, the majority of the projects in this cluster were aimed at supporting mainly the development of long-life products $(58.28 \%)$ and products made from low-impact materials $(29.01 \%)$. There are then smaller percentages of recyclable products, compostable or biodegradable products, and use efficient products. Projects grouped in this cluster can be interpreted adopting a framework for differentiating categories of environmentally oriented entrepreneurship proposed by Schaltegger [56, 57] and Petersen [58]. Hörisch [86], adopting such a framework for differentiating sustainable crowdfunding projects from two German platforms found that most of them can be identified as bioneers. The characteristics of projects grouped in cluster 2 , in terms of the amount raised by the campaign and number of financers, seem consistent with projects for market niches. A relevant example of a product made from low-impact materials belonging to this cluster is represented by the one developing technical outerwear realized with a recycled fabric. The nature of the product fits well with the idea that these products might be addressed to market niches serving specific customers. For these reasons the project cluster can be named "Crowdfunding bioneers"; and they can contribute to a sustainable transition by means other than directly influencing incumbents. For instance, their activities can serve as benchmarks demonstrating that higher levels of sustainability in some fields are possible [56].

Cluster 3 is represented by a small percentage of projects financed with sensibly above-average support, received both in terms of amount raised in the campaign and number of financers. Projects grouped in this cluster are also characterized by an overall average amount requested by the crowdfunding campaign, which suggests that such a target was rationally set [87]. These projects, that significantly outperform the others, seem quite similar to the "blockbuster projects" identified by Liu and colleagues [88] and thus extremely successful, influential and might exhibit positive spill-over effects. It is interesting to notice that all of these projects adopted quite specific sustainability keywords to describe their product. Digging deeper in this cluster, the majority of the projects aim at supporting mainly the development of long-life products $(65.77 \%)$ and products made from low-impact materials $(20.45 \%)$, while a smaller percentage are developing energy-efficient products (13.6\%). Finally, none of the projects support the development of recyclable products and compostable or biodegradable products. A relevant example of a long-life product among the projects grouped in this cluster can be represented by a microwave-to-erase, digitally connected notebook that can be reused many times thus avoiding the necessity to produce additional notebooks and reducing the generation of waste as well. Another 


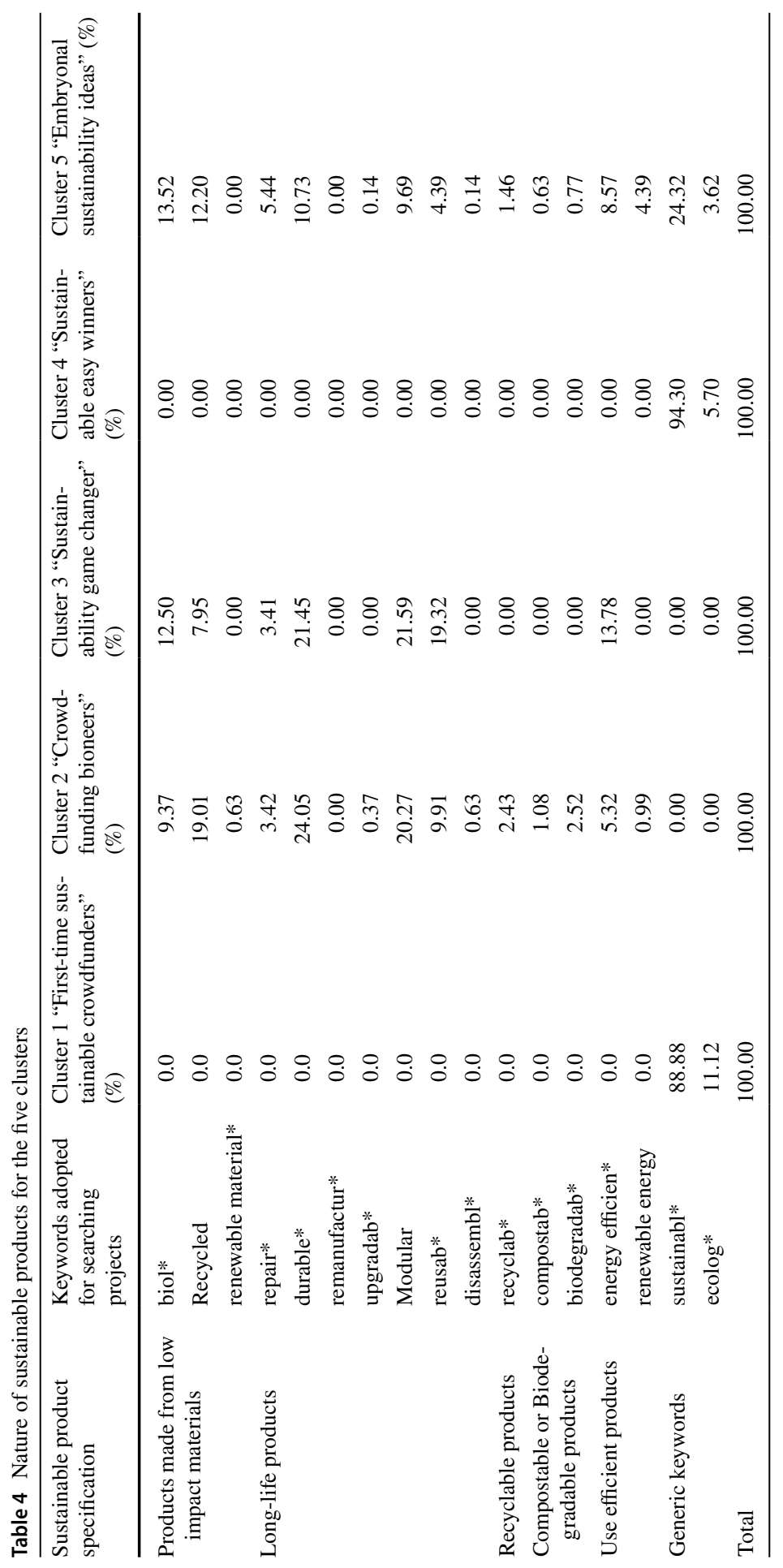


example of a product made from low-impact materials is represented by a jumper made of spent coffee grounds and recycled plastic from bottles that are used to create the fibers of the wearable. These successful campaigns that pioneer the development of a sustainable product act as market validators and may encourage emulators to enter the market and also incrementally develop the product, as has happened in many successful campaigns [88, 89]. The motivations presented before the cluster can be named as "Sustainability game changers" considering the fact that the cluster group's few projects have a high impact potential on the development of sustainable products.

In cluster 4 we have grouped 421 projects successfully financed with a slightly lower than average support, received both in terms of amount raised in the campaign and the number of financers. These projects are also characterized by a slightly lower than average amount requested for the crowdfunding campaign. Mollick [63], analyzing the dynamics of Kickstarter projects in terms of success and failure, suggests that most of the successful projects are quite small in terms of amount requested, with only a few thousand dollars in funding. The tendency to set quite a low amount of money can be explained by the rules of Kickstarter and Indiegogo to release funding on an all-or-nothing basis and thus making small projects relatively easier to plan and win. The clustering procedure assigned to this cluster, in this case, only includes projects adopting quite generic sustainable keywords to describe their product. As suggested for cluster 1, this can be attributed to the willingness of project creators to ride the wave of sustainability that is encountering a large number of customers at the present time. For instance, several projects belonging to this cluster have been related to the development of sustainable clothing (i.e. jumpers, t-shirt, scarfs) All of these campaigns introduce their product as "sustainable" or "ecological" without providing much more information. For all the reasons explained above, the cluster group can be named "Sustainable easy winners" projects.

Finally, cluster 5 groups a relevant percentage of projects not financed. These projects present the lowest values in respect of the average amount of support received, both in terms of amount raised in the campaign and number of financers. Projects grouped in this cluster are also marked by a slightly lower than average amount requested in the crowdfunding campaign. It is interesting to note that several $(72.0 \%)$ of these projects adopted quite specific keywords to describe their sustainable product. Exploring the contribution towards sustainability that these projects attempted, the majority of them related to long-life products $(30.52 \%)$, followed by products made from low impact materials $(25.71 \%)$ and use efficient products $(12.96 \%)$. Only a small number of projects aspired to contribute to the development of recyclable products $(1.46 \%)$ and compostable or biodegradable products $(1.40 \%)$. The patterns presented by projects grouped in cluster 5 are consistent with the dynamics described by the seminar work of Mollick [57], suggesting that in crowdfunded projects "failures happen by large amounts". Indeed in cluster 5, the projects that failed reported an overall mean amount funded of $15.2 \%$ of the goal. The relevant literature on crowdfunding suggests that quality of the projects is a strong determinant of the success of the campaigns $[90,91]$. Quality, in the case of crowdfunded products, is related to the functional aspects 
of the products themselves that can be reflected by an accurate description, a detailed explanation of the functionalities, and also by a precise definition of the development stage of the idea. In conclusion, it can be argued that the potential contribution to the development of sustainable products by the campaigns grouped in cluster 5 is practically non-existent, either because the idea was found to be in an embryonal stage or not meeting the adequate quality standards, or because it not demanded by the market. For all the reasons mentioned above, the cluster group can be named "Embryonal sustainability ideas", not yet ready for the market.

\subsection{Predicting the success of sustainable products' crowdfunding campaigns}

This section presents the results of the logistic regression analysis, showing the factors that might predict the success of sustainable product campaigns. In particular, this section aims at presenting the results of the research hypothesis investigating the adoption of specific vs generic keywords in determining the success of a project. The results presented in Table 5 show that all variables tested are significant drivers in the success of a sustainable crowdfunding initiative. In line with previous research $[63,66,87]$, there is a significant negative correlation between the funding goal and the probability of success, supporting that an increase in the project funding goal is correlated with a lower probability of success. Therefore, $\mathrm{H} 1$ is supported.

Regression results also show that the duration of the crowdfunding campaign (in days) has a negative and significant influence on the success of the project; the longer the funding period, the less likely the success probability [61, 63, 65]. Hence, $\mathrm{H} 2$ is also supported.

The number of words used to describe the project represents the method by which the project launchers stimulate and persuade potential supporters of the project. Also in this case, as for other research in the field [73, 74], there is a significant and positive relationship between the variables. The longer the description of the project, the higher its success probability. Consequently, H3 is also supported.

Finally, regression results confirm a positive and significant relationship between the adoption of specific keywords for sustainable product descriptions (e.g. repairable, recycled) and the success of the initiative. The more generic the sustainable keywords associated are (i.e. sustainable, ecologic), the lower the success probability of the project. As a consequence, H4 is also supported.

\section{Conclusions}

This exploratory research analyses the contribution of reward-based crowdfunding platforms (i.e. Kickstarter and Indiegogo) as financial instruments to support the development of sustainable products. The search procedure adopted allowed us to identify 3082 projects strictly related to sustainability which represents a relatively small percentage (i.e. about $1.5 \%$ ) of the total projects published on both platforms since 2009. Relevant characteristics of the projects retrieved were identified using a 


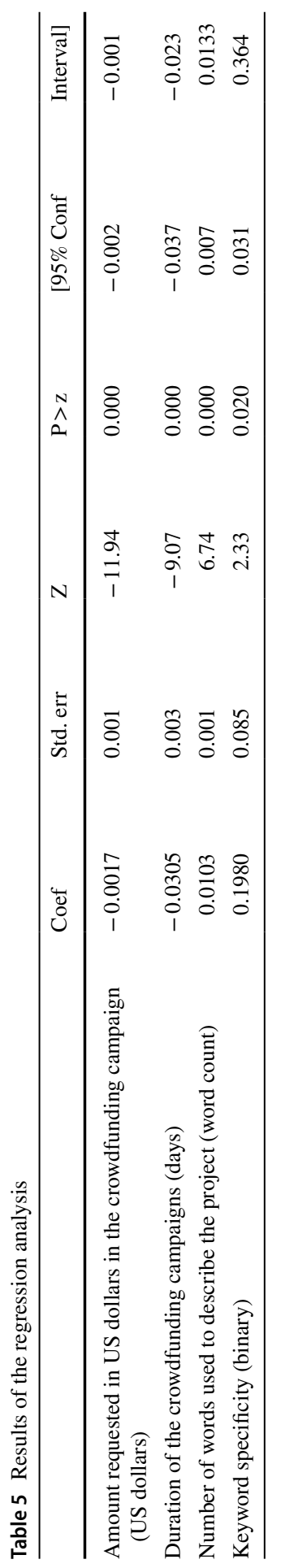


clustering procedure and interpreted using the relevant literature in the field. Cluster taxonomy allowed us to distinguish between five clusters: "First-time sustainable crowdfunders", "Crowdfunding bioneers", "Sustainability game changer", "Sustainable easy winners" and "Embryonal sustainability ideas". Only 88 highly successful projects (i.e. "Sustainability game changer") can also be considered to have a high impact potential to contribute to the pathway to more sustainability by directly influencing incumbents.

Even if the results of the investigation showed that nowadays the impact of crowdfunding in supporting the development and commercialization of sustainable products seems quite marginal, the potential of the instruments is enormous. During the last few years, new crowdfunding platforms have emerged that were specifically made for hosting projects that can achieve a sustainable impact. Relevant examples are Oneplanetcrowd and TousNosProjets. In these cases, a managerial suggestion for the platforms on which the research is grounded would be to introduce a specific project category for sustainable products. Project categories are used by Kickstarter and Indiegogo to allocate projects in different sections, and therefore improve their discoverability by potential supporters. Indeed, projects aiming at funding sustainable products might be overwhelmed by the other ones, thus having lower visibility.

Moreover, the paper also contributes to the literature on success factors of crowdfunding initiatives and the development of the information diagnosticity theory. Even if there is much research providing a comprehensive view on the factors explaining the success probability of a project, none of them have a specific focus on the adoption of certain terminology for describing sustainable products. In relation to this aspect, the present research underlines how adopting just a generic keyword (i.e. sustainable or ecologic) to describe a sustainable product might weaken the success probability of the project. Taking all of this into account, it seems that crowdfunding financers are quite aware of such issues and therefore refusing to support products that are presented with some vague claim of sustainability.

Despite the relevance of the results, there are some limitations to be acknowledged. Firstly, the analysis relies on a set of keywords that should identify the projects seeking financial support on crowdfunding platforms that somehow address sustainability. Even if the selection of these keywords has been made with the support of the relevant literature on sustainable product design, potential bias can be nested in such an approach. Moreover, it has to be noted that neither platform (i.e. Kickstarter and Indiegogo) performs any verification of the sustainability claims of the projects hosted and this might have an impact on the analysis presented. In such a context, future research can explore the role of greenwashing (i.e. an unethical marketing practice where products are depicted as environmentally friendly without fundamentally being so) that can be enacted in crowdfunding campaigns and how crowdfunding platforms and financers are informed about the issue. Still, in such context, a managerial suggestion for the platforms under analysis might be to focus their efforts on developing a standardized procedure to verify the sustainability claims of the projects. 
The analysis paves the way for additional research to be conducted in this field; grounding on the numerous studies that already explore the interaction between creators and financers [92] and the importance of co-design sustainable products together with users [93]. Future research could investigate how crowdfunding project creators might effectively interact with supporters in the development of sustainable products. Finally, future research might also consider how the underlining concepts of crowdfunding and sustainability have evolved, starting from the first campaigns in 2009 until today.

Funding Open access funding provided by Scuola Superiore Sant'Anna within the CRUI-CARE Agreement.

\section{Declaration}

Conflict of interest The authors state that there is no conflict of interest.

Open Access This article is licensed under a Creative Commons Attribution 4.0 International License, which permits use, sharing, adaptation, distribution and reproduction in any medium or format, as long as you give appropriate credit to the original author(s) and the source, provide a link to the Creative Commons licence, and indicate if changes were made. The images or other third party material in this article are included in the article's Creative Commons licence, unless indicated otherwise in a credit line to the material. If material is not included in the article's Creative Commons licence and your intended use is not permitted by statutory regulation or exceeds the permitted use, you will need to obtain permission directly from the copyright holder. To view a copy of this licence, visit http://creativecommons.org/licen ses/by/4.0/.

\section{References}

1. Hill, M. K. (2020). Understanding environmental pollution. Cambridge University Press.

2. Haustein, K., Allen, M. R., Forster, P. M., Otto, F. E. L., Mitchell, D. M., Matthews, H. D., \& Frame, D. J. (2017). A real-time global warming index. Scientific reports, 7(1), 1-6.

3. Rajapaksa, D., Islam, M., \& Managi, S. (2017). Natural capital depletion: The impact of natural disasters on inclusive growth. Economics of Disasters and Climate Change, 1(3), 233-244.

4. Mazzanti, M., \& Zoboli, R. (2008). Waste generation, waste disposal and policy effectiveness: Evidence on decoupling from the European Union. Resources, Conservation and Recycling, 52(10), 1221-1234.

5. Ramesh, B. R. (2003). Biodiversity conservation and management. Tropical Ecology, 44(1), 85-91.

6. Ekins, P. (2011). Environmental sustainability: From environmental valuation to the sustainability gap. Progress in Physical Geography, 35(5), 629-651.

7. WCED (1987) Our Common Future: Report of the World Commission on Environment and Development, WCED: Switzerland.

8. Morelli, J. (2011). Environmental sustainability: A definition for environmental professionals. Journal of environmental sustainability, 1(1), 2.

9. Corsini, F., Rizzi, F., \& Frey, M. (2017). Extended producer responsibility: The impact of organizational dimensions on WEEE collection from households. Waste Management, 59, 23-29.

10. Chertow, M. R. (2007). Uncovering industrial symbiosis. Journal Of Industrial Ecology, 11(1), 11-30.

11. Rizzi F, Bartolozzi I, Borghini A, Frey M. 2012. Environmental Management of End-of-Life Products: Nine Factors of Sustainability in Collaborative Networks. Business Strategy and the Environment. 
12. Bautista-Lazo, S., \& Short, T. (2013). Introducing the All Seeing Eye of Business: A model for understanding the nature, impact and potential uses of waste. Journal Of Cleaner Production, 40, $141-150$.

13. Worrell, E., \& Reuter, M. A. (2014). Recycling in Context Handbook of Recycling.

14. Handfield, R. B., Melnyk, S. A., Calantone, R. J., \& Curkovic, S. (2001). Integrating environmental concerns into the design process: The gap between theory and practice. IEEE Transactions on Engineering Management, 48(2), 189-208.

15. Ortas, E., Burritt, R. L., \& Moneva, J. M. (2013). Socially Responsible Investment and cleaner production in the Asia Pacific: Does it pay to be good? Journal of Cleaner Production, 52, 272-280.

16. Salo, H. H., Suikkanen, J., \& Nissinen, A. (2020). Eco-innovation motivations and ecodesign tool implementation in companies in the Nordic textile and information technology sectors. Business Strategy and the Environment, 29(6), 2654-2667.

17. Singh, P. K., \& Sarkar, P. (2019). A framework based on fuzzy AHP-TOPSIS for prioritizing solutions to overcome the barriers in the implementation of ecodesign practices in SMEs. International Journal of Sustainable Development \& World Ecology, 26(6), 506-521.

18. Belleflamme, P., Lambert, T., \& Schwienbacher, A. (2014). Crowdfunding: Tapping the right crowd. Journal of Business Venturing, 29(5), 585-609.

19. Roma, P., Petruzzelli, A. M., \& Perrone, G. (2017). From the crowd to the market: The role of reward-based crowdfunding performance in attracting professional investors. Research Policy, 46(9), 1606-1628.

20. Lehner, O. M., \& Nicholls, A. (2014). Social finance and crowdfunding for social enterprises: A public-private case study providing legitimacy and leverage. Venture Capital, 16(3), 271-286.

21. Petruzzelli, A. M., Natalicchio, A., Panniello, U., \& Roma, P. (2019). Understanding the crowdfunding phenomenon and its implications for sustainability. Technological Forecasting and Social Change, 141, 138-148.

22. Testa, S., Nielsen, K. R., Bogers, M., \& Cincotti, S. (2019). The role of crowdfunding in moving towards a sustainable society. Technological Forecasting and Social Change, 141, 66-73.

23. Bhamra, T., \& Lofthouse, V. (2007). Design for sustainability: a practical approach, Gower Publishing, Ltd..

24. Mestre, A., \& Cooper, T. (2017). Circular product design. A multiple loops life cycle design approach for the circular economy. The Design Journal 20(sup1): S1620-S1635.

25. Shogren, R., Wood, D., Orts, W., \& Glenn, G. (2019). Plant-based materials and transitioning to a circular economy. Sustainable Production and Consumption, 19, 194-215.

26. Bodar, C., Spijker, J., Lijzen, J., Waaijers-van der Loop, S., Luit, R., Heugens, E., \& Traas, T. (2018). Risk management of hazardous substances in a circular economy. Journal of Environmental Management, 212, 108-114.

27. Bocken, N. M., De Pauw, I., Bakker, C., \& Van Der Grinten, B. (2016). Product design and business model strategies for a circular economy. Journal of Industrial and Production Engineering, 33(5), 308-320.

28. Guide, V. D. R., Jr. (2000). Production planning and control for remanufacturing: Industry practice and research needs. Journal of operations Management, 18(4), 467-483.

29. Linton, J. D., \& Jayaraman, V. (2005). A framework for identifying differences and similarities in the managerial competencies associated with different modes of product life extension. International journal of production research, 43(9), 1807-1829.

30. Hazen, B. T., Mollenkopf, D. A., \& Wang, Y. (2017). Remanufacturing for the circular economy: An examination of consumer switching behavior. Business Strategy and the Environment, 26(4), 451-464.

31. Jayaraman, V. (2006). Production planning for closed-loop supply chains with product recovery and reuse: An analytical approach. International Journal of Production Research, 44(5), 981-998.

32. McDonough, W., \& Braungart, M. (2010). Cradle to cradle: Remaking the way we make things, North point press.

33. Geyer, R., Kuczenski, B., Zink, T., \& Henderson, A. (2016). Common misconceptions about recycling. Journal of Industrial Ecology, 20(5), 1010-1017.

34. Clark, J. H., Farmer, T. J., Herrero-Davila, L., \& Sherwood, J. (2016). Circular economy design considerations for research and process development in the chemical sciences. Green Chemistry, 18(14), 3914-3934. 
35. Vert, M., Doi, Y., Hellwich, K., Hess, M., Hodge, P., Kubisa, P., Rinaudo, M., \& Schué, F. (2012). Terminology for biorelated polymers and applications. Pure Applied Chemistry, 84, 377-410.

36. Herring, H., \& Roy, R. (2007). Technological innovation, energy efficient design and the rebound effect. Technovation, 27(4), 194-203.

37. Boks, C., \& McAloone, T. C. (2009). Transitions in sustainable product design research. International Journal of Product Development, 9(4), 429-449.

38. Söderholm, P., \& Tilton, J. E. (2012). Material efficiency: An economic perspective. Resources, conservation and recycling, 61, 75-82.

39. Howe, J. (2006). "Crowdsourcing: A Definition'” Track Rise Amat Weblog. http://crowdsourcing. typepad.com/cs/2006/06/crowd

40. Marelli, A., \& Ordanini, A. (2016). What makes crowdfunding projects successful 'before' and 'during'the campaign?. In: Crowdfunding in Europe, (pp. 175-192). Springer, Cham.

41. Bruton, G., Khavul, S., Siegel, D., \& Wright, M. (2015). New financial alternatives in seeding entrepreneurship: Microfinance, crowdfunding, and peer-to-peer innovations. Entrepreneurship Theory and Particle

42. Zhou, S., Ma, T., \& Liu, Z. (2021). Crowdfunding as a screener for collective investment. Electronic Commerce Research 1-27.

43. Marchegiani, L. (2018). From Mecenatism to crowdfunding: Engagement and identification in cultural-creative projects. Journal of Heritage Tourism, 13(2), 143-151.

44. Bassani, G., Marinelli, N., \& Vismara, S. (2019). Crowdfunding in healthcare. The Journal of Technology Transfer, 44(4), 1290-1310.

45. Kunz, M. M., Bretschneider, U., Erler, M., \& Leimeister, J. M. (2017). An empirical investigation of signaling in reward-based crowdfunding. Electronic Commerce Research, 17(3), 425-461.

46. Chan, C. R., \& Parhankangas, A. (2017). Crowdfunding innovative ideas: How incremental and radical innovativeness influence funding outcomes. Entrepreneurship Theory and Practice, 41(2), 237-263.

47. Zheng, H., Qi, Z., Luo, X., Li, L., \& Xu, B. (2018). The value of backers' word-of-mouth in crowdfunding projects filtering: an empirical investigation. Electronic Commerce Research 1-26.

48. Van Hemel, C., \& Cramer, J. (2002). Barriers and stimuli for ecodesign in SMEs. Journal of cleaner production, 10(5), 439-453.

49. Stanko, M. A., \& Henard, D. H. (2017). Toward a better understanding of crowdfunding, openness and the consequences for innovation. Research Policy, 46(4), 784-798.

50. Da Cruz, J. V. (2018). Beyond financing: Crowdfunding as an informational mechanism. Journal of Business Venturing, 33(3), 371-393.

51. Drover, W., Busenitz, L., Matusik, S., Townsend, D., Anglin, A., \& Dushnitsky, G. (2017). A review and road map of entrepreneurial equity financing research: Venture capital, corporate venture capital, angel investment, crowdfunding, and accelerators. Journal of management, 43(6), 1820-1853.

52. Rousseaux, P., Gremy-Gros, C., Bonnin, M., Henriel-Ricordel, C., Bernard, P., Floury, L., \& Vincent, P. (2017). "Eco-tool-seeker": A new and unique business guide for choosing ecodesign tools. Journal of Cleaner Production, 151, 546-577.

53. Rossi, M., Germani, M., \& Zamagni, A. (2016). Review of ecodesign methods and tools. Barriers and strategies for an effective implementation in industrial companies. Journal of Cleaner Production, 129, 361-373.

54. Sanders, E. B. N., \& Stappers, P. J. (2008). Co-creation and the new landscapes of design. CoDesign, 4(1), 5-18.

55. Brown, T. E., Boon, E., \& Pitt, L. F. (2017). Seeking funding in order to sell: Crowdfunding as a marketing tool. Business Horizons, 60(2), 189-195.

56. Schaltegger, S. (2002). A framework for ecopreneurship. Greener management international 2002: $38-45$.

57. Schaltegger, S. (2005). A framework and typology of ecopreneurship: Leading bioneers and environmental managers to ecopreneurship. Making Ecopreneurs: Developing sustainable entrepreneurship 43-60.

58. Petersen, H. (2010). The competitive strategies of ecopreneurs: Striving for market leadership by promoting sustainability. Making Ecopreneurs: Developing Sustainable Entrepreneurship, 2, 223-236.

59. Vismara, S. (2019). Sustainability in equity crowdfunding. Technological Forecasting and Social Change, 141, 98-106. 
60. Mitra, T., \& Gilbert, E. (2014). The language that gets people to give: Phrases that predict success on kickstarter. In: Proceedings of the 17th ACM conference on Computer supported cooperative work \& social computing (pp. 49-61).

61. Xiao, S., Tan, X., Dong, M. and J. Qi. (2014). How to Design Your Project in the Online Crowdfund- ing Market? Evidence from Kickstarter. In: Proceedings of the Thirty Fifth International Conference on Information Systems, Auckland: Australia.

62. Etter, V., Grossglauser, M., \& Thiran, P. (2013). Launch hard or go home! Predicting the success of Kickstarter campaigns. In: Proceedings of the first ACM conference on Online social networks (pp. 177-182)

63. Mollick, E. (2014). The dynamics of crowdfunding: An exploratory study. Journal of business venturing, 29(1), 1-16.

64. Chen, M., Liu, Z., Ma, C., \& Gong, X. (2019). A distinctive early bird price in reward-based crowdfunding. Electronic Commerce Research 1-24.

65. Koch, J. A., \& Siering, M. (2019). The recipe of successful crowdfunding campaigns. Electronic Markets, 29(4), 661-679.

66. Cordova, A., Dolci, J., \& Gianfrate, G. (2015). The determinants of crowdfunding success: Evidence from technology projects. Procedia-Social and Behavioral Sciences, 181, 115-124.

67. Beier, M., \& Wagner, K. (2014). Crowdfunding Success of Tourism Projects-Evidence from Switzerland. Available at SSRN 2520925.

68. de Larrea, G. L., Altin, M., \& Singh, D. (2019). Determinants of success of restaurant crowdfunding. International Journal of Hospitality Management, 78, 150-158.

69. Kuppuswamy, V., \& Bayus, B. L. (2018). Crowdfunding creative ideas: The dynamics of project backers. In: The economics of crowdfunding (pp. 151-182). Palgrave Macmillan, Cham.

70. Kirmani, A., \& Rao, A. R. (2000). No pain, no gain: A critical review of the literature on signaling unobservable product quality. Journal of marketing, 64(2), 66-79.

71. Jiang, Z., \& Benbasat, I. (2004). Virtual product experience: Effects of visual and functional control of products on perceived diagnosticity and flow in electronic shopping. Journal of Management Information Systems, 21(3), 111-147.

72. Mudambi, S. M., \& Schuff, D. (2010). Research note: What makes a helpful online review? A study of customer reviews on Amazon. com. MIS Quarterly 185-200.

73. Zhou, M. J., Lu, B., Fan, W. P., \& Wang, G. A. (2018). Project description and crowdfunding success: An exploratory study. Information Systems Frontiers, 20(2), 259-274.

74. Liang, X., Hu, X., \& Jiang, J. (2020). Research on the effects of information description on crowdfunding success within a sustainable economy-the perspective of information communication. Sustainability, 12(2), 650.

75. Özdemir, V., Faris, J., \& Srivastava, S. (2015). Crowdfunding 2.0: the next-generation philanthropy: A new approach for philanthropists and citizens to co-fund disruptive innovation in global health. EMBO Reports 16(3): 267-271.

76. Pimonenko, T., Bilan, Y., Horák, J., Starchenko, L., \& Gajda, W. (2020). Green brand of companies and greenwashing under sustainable development goals. Sustainability, 12(4), 1679.

77. Webrobots. (2020). "Kickstarter Datasets" https://webrobots.io/kickstarter - datasets. Accessed 2 Jan 2021.

78. Hair, J.F., Anderson, R.E., Tatham, R.L., Black, W.C. (1998). Multivariate data analysis, (5th Ed.), Pearson Prentice Hall.

79. Makles, A. (2012). Stata tip 110: How to get the optimal k-means cluster solution. The Stata Journal, 12(2): 347-351.

80. Schwarz, A. (2008). Lokale Scoring-Modelle. Eul Verlag.

81. O'brien, R. M. (2007). A caution regarding rules of thumb for variance inflation factors. Quality \& quantity 41(5): 673-690.

82. Hosseini Amereei, S. A. (2018). Learning and Performance in Serial Crowdfunding (Master's thesis, Haskayne School of Business).

83. Tversky, A., \& Kahneman, D. (2004). Extensional versus intuitive reasoning: The conjunction fallacy in probability judgment. Preference, belief, and similarity: Selected writings by Amos Tversky, 221-56. 
84. Garetti, M., \& Taisch, M. (2012). Sustainable manufacturing: Trends and research challenges. Production planning \& control, 23(2-3), 83-104.

85. Reisch, L. A., Cohen, M. J., Thøgersen, J. B., \& Tukker, A. (2016). Frontiers in sustainable consumption research. GAIA-Ecological Perspectives for Science and Society, 25(4), 234-240.

86. Hörisch, J. (2018). 'Think big'or'small is beautiful'? An empirical analysis of characteristics and determinants of success of sustainable crowdfunding projects. International Journal of Entrepreneurial Venturing, 10(1), 111-129.

87. Kuppuswamy, V., \& Bayus, B. L. (2017). Does my contribution to your crowdfunding project matter? Journal of Business Venturing, 32(1), 72-89.

88. Liu, J., Yang, L., Wang, Z., \& Hahn, J. (2015). Winner takes all? The "blockbuster effect" in crowdfunding platforms.

89. Mollick, E., \& Robb, A. (2016). Democratizing innovation and capital access: The role of crowdfunding. California Management Review, 58(2), 72-87.

90. Courtney, C., Dutta, S., \& Li, Y. (2017). Resolving information asymmetry: Signaling, endorsement, and crowdfunding success. Entrepreneurship Theory and Practice, 41(2), 265-290.

91. Parhankangas, A., \& Renko, M. (2017). Linguistic style and crowdfunding success among social and commercial entrepreneurs. Journal of Business Venturing, 32(2), 215-236.

92. Wang, N., Li, Q., Liang, H., Ye, T., \& Ge, S. (2018). Understanding the importance of interaction between creators and backers in crowdfunding success. Electronic Commerce Research and Applications, 27, 106-117.

93. Blomsma, F., Pigosso, D. C., \& McAloone, T. C. (2019). A theoretical foundation for developing a prescriptive method for the co-design of circular economy value chains. In: Proceedings of the Design Society: International Conference on Engineering Design (Vol. 1, No. 1, pp. 3141-3150), Cambridge University Press

Publisher's Note Springer Nature remains neutral with regard to jurisdictional claims in published maps and institutional affiliations. 